\title{
On Constructing Generative Mechanism for EFL Autonomous Learning Behaviors within Ubiquitous Learning Community
}

\author{
Huan-Huan Ren \\ Teaching and Research Institute of Foreign Languages \\ Bohai University, \\ Jinzhou, China \\ E-mail: renhuanhuan2014@163.com
}

\author{
Chi Ma \\ Jinzhou Institute of Forestry Research \\ Jinzhou Forestry Bureau, \\ Jinzhou, China \\ E-mail: machi2014@tom.com
}

\begin{abstract}
The ubiquitous computing movement makes computers much smarter and easier to use, and gives rise to ubiquitous learning which will truly revolutionize future education. With those enabling technologies, "Internet plus" strategy and natural shift from e-learning to u-learning are proposed as two dominating guidelines for EFL autonomous learning within u-learning community. Besides, several generative mechanism for EFL autonomous learning behaviors including generative mechanism for motivated, targeted, adaptive, incentive, regulative and reflective autonomous learning behaviors, are suggested and analyzed, aiming to enhance the level of learner autonomy and drive broader learning improvement within u-learning community.
\end{abstract}

Keywords-generative mechanism; EFL autonomous learning; ubiquitous learning community

\section{INTRODUCTION}

The extremely rapid technical evolution, from wireless technologies, mobile technologies, all the way through to the latest state-of-the-art ubiquitous computing technologies, has opened up new opportunities for global citizens. As computing technologies grow, ubiquitous learning (ulearning) has risen to the forefront of education, and is potentially the next big step for education. It's clear to see the far-reaching benefits of education based on u-learning communication. A growing research area pertinent to ubiquitous learning has merged both at home and abroad recent years, and many scholars try to argue for establishing fully interactive ubiquitous learning environments for future learners. In light of this, taking EFL (English as Foreign Language) learning into concern, this research aims at finding out generative mechanism for EFL autonomous learning behaviors within u-learning community. In this paper, literature review, dominating guidelines and pedagogical analysis regarding EFL autonomous learning behaviors within u-learning community are proposed and analyzed so as to ultimately enhance the level of learner autonomy and drive broader learning improvement.

\section{LITERATURE REVIEWS ON UBIQUITOUS COMPUTING AND UBIQUITOUS LEARNING}

\section{A. Ideas about Ubiquitous Computing}

Ubiquitous computing, often abbreviated to "ubicomp", is coined by Mark Weiser, who is known as the father of ubiquitous computing due to initiating research work at Xerox Palo Alto Research Center (PARC) in 1988. Weiser believes that computers should vanish in the background allowing people to concentrate on their tasks, and sets it as the goal of the ubiquitous computing [1]. Alan Kay of Apple calls this "Third Paradigm" computing, or say, the third wave of the computing revolution following the first and second waves, or trends, which are mainframe computing and personal computing. The mainframe era has many situations where there is a single computer and many people using it, while in the personal computing era, the current era, every person has one or two computers. And in the era of ubiquitous computing, there is one person benefiting from many computers [2]. The idea behind the age of ubiquitous computing, the new genre of computing, is calm technology. Just as Weiser put it, the most profound technologies are those that disappear [3]. Ubiquitous computing is to make a computer so imbedded, so fitting, so natural, so unobtrusive that we use it without even thinking about it [4]. In other words, the computer is no longer the focus of human attention, but rather, becomes invisible, transparent or distraction-free to the user. Ubiquitous computing creates a new kind of relationship between people and computers, as computer completely permeates the life of the user [5].

\section{B. Ubiquitous Learning (U-learning)}

According to Cope, B. \& Kalantzis, M., ubiquitous learning (i.e. u-learning) is a new educational paradigm made possible in part by the affordances of digital media (i.e. omnipresence of digital media, supporting new modes of knowledge creation, communication, and access) [6]. Three main characteristics of ubiquitous learning can be summarized, namely invisibility, accessibility and adaptability, in that computers are effectively invisible in use, wireless and networked in motion, and accurately meet the communication needs, modes and styles of the user, so that learning can occur anytime and anyplace [7]. Technological movements supporting ubiquitous learning such as nanotechnology, wireless computing, context-awareness and natural interaction, to name a few, are already well underway and provide an emerging opportunity for the maturity (or say, survive and thrive) of ubiquitous learning. However, as Cope, B. \& Kalantzis, M. observe, there is no directly deterministic relationship between technology and social change [8]. The key of paradigm shift in education is not the logic or technical specifications of the machines. Rather it is the new 
ways in which meaning is created, stored, delivered and accessed. In this sense, technologies are the product of social needs, and education, not technology, was the driver of ubiquitous learning [9].

\section{Changes in Autonomous Learning Environment}

Learning autonomy is regarded as learning ecology, a science dealing with the relationship between learners and the environment that learners are situated in [10]. The introduction of computer-based technologies completely revolutionizes the learning environment, and thereby optimizes autonomous learning behaviors of EFL students in pervasive environment. Learners can get access to a wealth of information and reach out to people from all walls of life at any time and at any place supported by a widespread network and ubiquitous computing technologies. Moreover everyday objects, such as mobile phones, televisions, personal digital assistants, to name a few, are more computerlike or have computer power (embedded computer systems) built in, or are even computers themselves. As learning devices are becoming considerably more powerful yet much smaller, the user is not preoccupied with the dual tasks of using the computer and getting the services, resources, or information. These adaptive learning scenarios give rise to more autonomous learning behaviors of EFL learners. High learner autonomy can be easily cultivated and enhanced in such interactive situation, and learners are more likely to have exciting and successful experience in EFL learning.

\section{DOMINATING GUIDELINES FOR EFL AUTONOMOUS LEARNING WITHIN U-LEARNING COMMUNITY}

\section{A. “Internet Plus" Strategy}

Internet and other information technology should be integrated into EFL autonomous learning behaviors, as EFL learners are more likely to be self-centered with the aid of smart technologies. Not only is it a trend occurring in the international arena, but also a popular action plan pursued and sought by China's government. Speaking at the March 5 opening meeting of the National People's Congress of China, Premier Li Keqiang unveiled "Internet Plus" concept in his 2015 Government Work Report. He said that, "We will develop the 'Internet Plus' action plan to integrate the mobile Internet, cloud computing, big data, and the Internet of Things with modern manufacturing, to encourage the healthy development of e-commerce, industrial networks, and Internet banking, and to guide Internet-based companies to increase their presence in the international market" [11]. Li Keqiang also mentioned the policy goals of three network convergence, accelerating fiber optic network construction, improving broadband speed and promoting information consumption. The educational department should be also highly involved into the "Internet plus" action plan and be an indispensable part of it. Internet technologies nurture the development and evolution of u-learning community and hence provide convenient environment for EFL autonomous learners.

In summary, Internet technologies will continue to grow, but you'd be missing a big part of the picture by underestimating the challenges and changing landscape happening in China's education. The key to "Internet plus" is also the "plus" of the education. "Internet plus" should be one measure learners have to adopt to address the low learner autonomy in traditional EFL classroom.

\section{B. From "E-learning" to "U-learning"}

Learning technologies have evolved significantly as technology industry advances, from e-learning, m-learning to u-learning. Electronic learning (e-learning), a concept first introduced in the 1960's, is the collective name for all forms of learning across electronic media, which can include computer based learning, web based learning or simply, virtual education, digital collaboration. E-learning was the first real step towards using computers and applications for educational purposes. Due to the immobility of e-learning, m-learning supported by mobile technologies was developed to provide a mobile platform for the learner to interact with. However, u-learning isn't tantamount to the combination of e-learning plus m-learning. U-learning is more than that, as u-learning offers an adaptive, customized, context-aware solution for the future of education. Driven by sensor technologies in learning, u-learning takes advantage of learner's location, environment, proximity and situation to contextualizing the learning process. According to Yeonjeong Park, the conceptual shifts from e-learning to ulearning are articulated from two aspects, namely physical devices, and computation and communication learning [12]. The transition from e-learning to $u$-learning is a matter of innovation and evolution, and the implications of the profound transformation cannot be underestimated.

In short, e-learning is a method, while u-learning is an attitude; e-learning spans the course of study, while ulearning is life-long and life-wide; e-learning is focused on learning content, while u-learning is targeted for learning for a person. U-learning is seen to be a massive boost to education as it provides adaptive and omnipresent learning for students.

\section{PEDAGOGICAL ANALYSIS OF GENERATIVE MECHANISM FOR EFL AUTONOMOUS LEARNING BEHAVIORS WITHIN U-LEARNING COMMUNITY}

Ubiquitous computing lays the groundwork for ubiquitous learning, and requires us to make a shift in our education paradigms. Some generative mechanism (GM) for EFL autonomous learning behaviors (ALB) within ulearning community are suggested, shown in Fig. 1., including generative mechanism for EFL motivated, targeted, adaptive, incentive, regulative and reflective autonomous learning behaviors. 

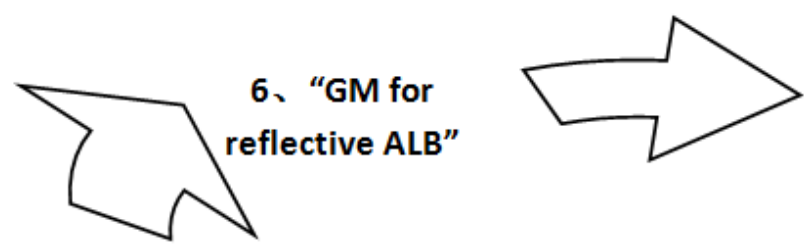

\section{1、"GM for motivated ALB"}

\section{5、"GM for regulative ALB"}

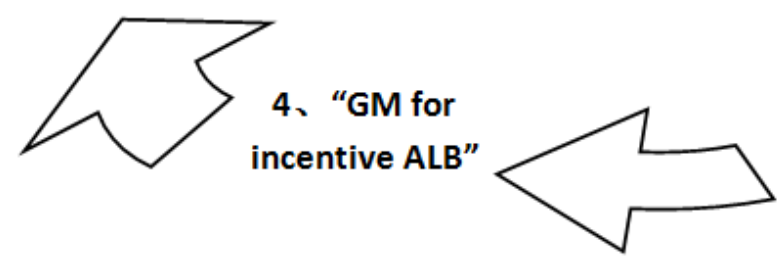

U-learning community

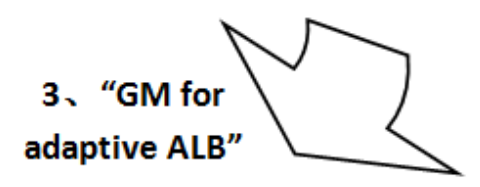

Figure 1. Generative mechanism (GM) for autonomous learning behaviors (ALB).

\section{A. Generative Mechanism for EFL Motivated Autonomous Learning Behaviors.}

As Albert Einstein said, "learning is experience, everything else is just information", and it's especially true to u-learning. Generative mechanism for EFL motivated autonomous learning behaviors within u-learning community can be carried out through two aspects. Firstly, EFL learners should be encouraged to love learning and u-learning. Through u-learning, personal meaning and values are sought, and intelligence and capability as a person is enhanced. Also, u-learning offers EFL learners opportunities for selfexploration and self-achievement, especially living in the pervasive digital era. Only learners do love learning itself, can the EFL learning process be possible, and can EFL students be highly engaged and involved in u-learning community. Anyway, motivation does make a difference. Secondly, the enthusiasm for EFL within u-learning community should be sustained and enhanced all way along. U-learning not only enhances learning by providing a personalized experience but also makes it more accessible. With enabling and smart technologies, EFL learners are drawn to extremely interesting and useful learning mode as opposed to dull and frustrating one. In this case, the pleasure and joy can be more likely to be realized within u-learning community.

\section{B. Generative Mechanism for EFL Targeted Autonomous Learning Behaviors.}

A hybrid of learning capacities, or multidisciplinary level of skills, should be targeted whilst establishing generative mechanism for EFL target autonomous learning behaviors. EFL students should be savvy about taking charge of themselves and being autonomous in learning all way along. Learner autonomy, as an indispensible and critical learning skill for learners, if not living skill, serves as a powerful means to harvest desirable learning outcomes. And it's also an ability that an informed citizen of an information society ought to possess to participate intelligently and actively in the society. U-learning community supports and nurtures a self-directed learning mode and gives it into full play. Moreover, EFL learners should remind themselves what to learn, how to learn, and take actions for personal development. What's more, English language proficiency should also be sought within u-learning community where more authentic and up-to-date resources are available and customized. And English learning is anticipated to be emerged, imbedded and fitted into personal life of the learner, just like the ubiquitous technologies do, so the true potential of learners in language skills can be realized and achieved.

\section{Generative Mechanism for EFL Adaptive Autonomous Learning Behaviors.}

U-learning community features an individualized, personalized and customized learning mode, and EFL learners in that environment must be adaptive, dynamic and flexible. EFL learners should focus on various contexts that arise in such environments, and choose the most satisfying solution that is suitable to their respective learning situation. Personalization in these scenarios have taken a new meaning as learners have various learning interests, needs, and styles, so to speak. This requires u-learning community to display appropriate pieces of information at the correct time based on physical surroundings, as opposed to just displaying all information. Through the use of state-of-the-art technologies, learners, as digital citizens, ought to make full use of context-aware information and increase English learning outcomes. Taking all the situations into consideration, learners should also find ways of overcoming possible difficulties, from the initial use of brand new multimedia technologies, right through to the analysis of customized 
information, so as to ultimately engage themselves in proper English language learning processes.

\section{Generative Mechanism for EFL Incentive Autonomous Learning Behaviors.}

In the area of generative mechanism for EFL incentive autonomous learning behaviors, an incentive framework should be highly sought and constructed. Enabling technologies do make a difference, but actions and behaviors which seek to put the needs and dynamics of learning ahead of the technologies that may support learning. EFL learners should be highly engaged into the process of self-exploration, instead of being involved in another part of traditional schooling. Meanwhile, communicative learning and collaborative learning are good ways of nurturing student's initiative. Social networking issues are anticipated to be integrated in the infrastructure of u-learning community, so that EFL learners can learn by interacting with other students through various activities. Since learning is never isolated independent learning, multi-pupil learning experiences can find its way within u-learning community. Lastly, it can be also an extremely valuable tool for students to deploy encouragement and award plans integrated into u-learning systems through the use of smart technologies. The proactive and positive learning behaviors generated by incentive schemes in EFL learning can lead to in-depth and tailored learning experience.

\section{E. Generative Mechanism for EFL Regulative Autonomous Learning Behaviors.}

The main benefit of generative mechanism of EFL regulative autonomous learning behaviors is to take real-time and on-going control of themselves for better learning outcomes. It's highly articulated by concrete actions in EFL learning. Firstly, learners should be in good control of learning resource. It's required that learners identify, locate, evaluate, and effectively use desired information for the issue or problem at hand. The selection and renewal of learning material is key to any efficient EFL learning. Moreover, learners take in their pace with flexible learning time and duration, which is proven to lead to a greater understanding. And student's learning actions are in accordance with learner's respective goals, abilities, interests. Meanwhile, multi-tasking and time management have become increasingly common in u-learning, and should be utilized by EFL learners within u-learning community. Lastly, learners can leverage different learning approaches to respond to learning contents and optimize learning outcomes. Enabling technologies applied in regulative autonomous learning behaviors are conducive to the efficiency and effectiveness of foreign language learning within u-learning community.

\section{F. Generative Mechanism for EFL Reflective Autonomous Learning Behaviors.}

There is a need for generative mechanism for EFL reflective autonomous learning behaviors which assist learners in getting deeper insights into their performance. Learners should never neglect the importance of feedbacks obtained from formative assessment and summative assessment. The results tracking, semantic web and data mining techniques are anticipated to be designed prior to the implantation of u-learning for possible reflection concerning EFL learning process. Hence, learners can trace themselves by knowing whether they are underachieving or not according to multiple criteria of EFL learning. It's suggested that recommendations and advice about their proper next learning actions be given to students, as fast and instant responses from u-learning community are conducive to the growth of EFL learners. What's more, learners can make predictions regarding the student's final performance based on the students' performance at interim tests, and in this process, more constructive thinking are generated for further learning actions and broader learning improvement.

\section{EPILOGUE}

The ubiquitous computing movement makes computers more helpful and easier to use, and gives rise to ubiquitous learning, a new learning paradigm which will truly revolutionize future education. U-learning incorporates the best characteristics of both e-learning and m-learning, as well as other new advances in technologies. It's argued that ulearning supports EFL autonomous learning behaviors, and some generative mechanism for EFL autonomous learning behaviors, including motivated, targeted, adaptive, incentive, regulative and reflective autonomous learning behaviors within u-learning community are suggested for future research and practice in EFL learning. All in all, although ulearning is still in the development and testing stages, ulearning will be a future learning mode over the next few years. More research ought to be dedicated towards ulearning so that the learning approach can provide more innovative learning experiences and opportunities for EFL learners with u-learning community.

\section{ACKNOWLEDGMENTS}

This work is part of the project of On Establishing Generative Mechanism of EFL Autonomous Learning Behaviors and Strengthening Development of Learning Field in Ubiquitous Learning Space, the project of On Cultivating and Developing Liaoning Scientific Foreign Language Talents with View to Bourdieu' Theory, and the project of On Constructing Mechanism and Strategies for College English Autonomous Learning Abilities via Mobile Multimedia. This research was supported by the fund of Liaoning Provincial Federation Social Science Circles (Project No. 2017lslktyb-019), the fund of Liaoning Planning of Philosophy and Social Science (Project No. L16CYY001), and the fund of the Thirteenth Five-Year Plan of Education Sciences of Liaoning Province (Project No. JG16DB013).

\section{REFERENCES}

[1] Weiser, M., The future of ubiquitous computing on campus. Commun. ACM, 1998.41(1).

[2] Weiser, M., http://www.ubiq.com/hypertext/weiser/UbiHome.html, Ubiquitous Computing.

[3] Weiser, M., The computer for the 21st century. SIGMOBILE Mob. computer communication review, 1999.3(3). 
[4] Weiser, M., http://www.ubiq.com/hypertext/weiser/UbiHome.html, Ubiquitous Computing.

[5] Weiser, M., Some computer science issues in ubiquitous computing; making computers available throughout the physical environment. Communications of the ACM, 1993. 36(7).

[6] Cope, B., \& Kalantzis, M., Ubiquitous learning: An agenda for educational transformation. In B. Cope \& M. Kalantzis (Eds.), Ubiquitous learning. Urbana, IL: University of Illinois Press, 2009.

[7] Ren, H.H., On establishing EFL teaching model to cultivate learner autonomy in ubiquitous network environment. 2nd International Conference on Future Computer Supported Education. Pennsylvania: DEStech Publications, Inc., 2015.

[8] Cope, B., \& Kalantzis, M., Ubiquitous learning: An agenda for educational transformation. In B. Cope \& M. Kalantzis (Eds.), Ubiquitous learning. Urbana, IL: University of Illinois Press, 2009.
[9] Cope, B., \& Kalantzis, M., Ubiquitous learning: An agenda for educational transformation. In B. Cope \& M. Kalantzis (Eds.), Ubiquitous learning. Urbana, IL: University of Illinois Press, 2009.

[10] Ren, H.H., Connotation and characteristics of independent study with perspective of educational ecology. Journal of Teaching and Management, 2016 (24).

[11] Li, K. Q., Report on the work of the government. See http://www.chinadaily.com.cn/china/2015twosession/201503/05/content_19729663.htm.

[12] Park, Y., A pedagogical framework for mobile learning: categorizing educational applications of mobile technologies intofour types. IRRODL, 2011. 12(2). 